\title{
OSTEONECROSIS DE LA CABEZA FEMORAL
}

E. GONZÁLEZ REIMERS ${ }^{\mathrm{a}}, \mathrm{M}$. ARNAY DE LA ROSA

Y J. VELASCO-VÁZQUEZc
${ }^{2}$ DEPARTAMENTO DE MEDICINA INTERNA. HOSPITAL UNIVERSITARIO DE CANARIAS. TENERIFE. 'DEPARTAMENTO DE PREHISTORIA, ANTROPOLOGÍA E HISTORIA ANTIGUA. UNIVERSIDAD DE LA LAGUNA. TENERIFE. 'UNIDAD DE PATRIMONIO HISTÓRICO. CABILDO DE GRAN CANARIA LAS PALMAS DE GRAN CANARIA. ESPAÑA.
La necrosis de la cabeza femoral es una entidad bien reconocida. Su etiología incluye lesiones traumáticas (fractura subcapital o transcervical del cuello de fémur) ${ }^{1}$ y no traumáticas, como alcoholismo, síndrome de Cushing (yatrogénico o no), hepatopatía crónica, embarazo, hemoglobinopatías, enfermedad de Gaucher, barotrauma, pancreatitis, hiperlipidemia, gota, vasculitis, sinovitis con elevación de la presión intraarticular, artritis juvenil, enfermedad celiaca, etc., por citar sólo algunas ${ }^{2-6}$, y varios fármacos ${ }^{7}$. Existen además raros casos familiares ${ }^{8}$.

La mayor parte de los casos se deben a alcoholismo o a tratamiento esteroideo. Se ha calculado la incidencia de esta entidad en pacientes que reciben corticoides: por cada 1.000 pacientes tratados con corticoides aparecería un caso de osteonecrosis cada año ${ }^{9}$, aunque en algunos casos la responsabilidad tal vez resida no en los propios corticoides, sino en la enfermedad subyacente (en muchos casos, de tipo vasculítico). En efecto, la necrosis isquémica desempeña un papel en su patogenia ${ }^{6}$; tras un episodio inicial de infarto, con necrosis ósea, se produce un colapso trabecular y formación de un secuestro. Una reacción osteosclerótica intensa de la región sana de la cabeza femoral genera el desarrollo de marcada osteofitosis y cambios artrósicos. Todo ello deforma la cabeza femoral de una manera bastante característica (tan sólo las formas graves de la enfermedad de Legg-Calvé-Perthes pueden dar lugar a una alteración similar ${ }^{10}$ ) y genera una imagen radiológica hiperden-

Correspondencia: E. González Reimers. Departamento de Medicina Interna.

Hospital Universitario de Canarias. Tenerife. Correo electrónico: egonrey@ull.es.

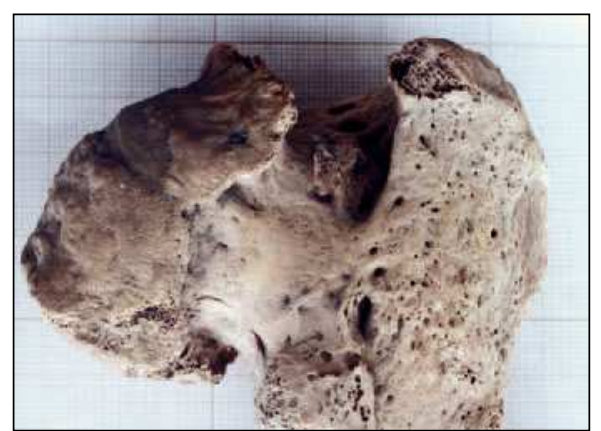

Fig. 1. Vista lateral de la cabeza femoral, con intensa osteofitosis y deformidad en champiñón.

sa a la que contribuyen las trabéculas colapsadas, el depósito de sales cálcicas en el área de secuestro y la intensa reacción reparativa osteosclerótica. Tanto la deformidad de la cabeza femoral (deformidad en seta o champiñón) como la intensa hiperdensidad radiológica son perfectamente visibles en las figuras que ilustran este caso (figs. 1 y 2).

Este caso, perteneciente a un individuo prehispánico de la isla de La Palma, inhumado en una cueva funeraria del Barranco del Agua (Garafía), excavada en su día por J. Pais Pais ${ }^{11}$ no presenta otras alteraciones que sugieran una etiología traumática. Se trata de un sujeto, probablemente varón por la robustez de las inserciones musculares, y adulto; la ausencia del resto del esqueleto no nos permite detectar signos sugestivos de otras entidades nosológicas causantes de osteonecrosis o procesos similares. El tipo de yacimiento y las características de la inhumación permiten adscribirlo a la población prehispánica de la isla de La Palma o benahoaritas (el término "guanche", en sentido estricto, hace referencia sólo a la población prehispánica de Tenerife, aunque, por extensión, se suele emplear para denominar a toda la población prehispánica de Canarias). Esta población prehis-

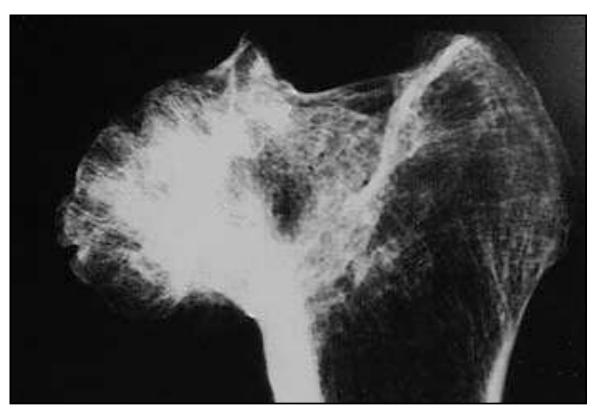

Fig. 2. Imagen radiológica de la cabeza femoral. Destaca la intensa osteosclerosis y el colapso de las trabéculas, que son sin embargo perfectamente visibles en la región trocantérea.

pánica es de origen bereber norteafricano ${ }^{12}$ y colonizó las islas, posiblemente en distintas oleadas, hace unos 2.500 años, aunque la antigüedad exacta del caso presentado no es conocida.

Que sepamos es éste el primer ejemplo de un caso de osteonecrosis en la población prehispánica de Canarias; no obstante, esta entidad ha sido descrita en otras poblaciones antiguas ${ }^{13}$.

\section{AGRADECIMIENTOS}

A J. Pais Pais, doctor en Historia, por habernos permitido estudiar este caso.

\section{BIBLIOGRAFÍA}

1. Lee JS, Suh KT. A pathological fracture of the femoral neck associated with osteonecrosis of the femoral head and a stress fracture of the contralateral femoral neck. J Arthroplasty. 2005;20:807-10.

2. Gebhard KL, Marbach HI. Relationship between systemic corticosteroids and osteo necrosis. Am J Clin Dermatol. 2001;2:377-88.

3. Saville PD. Alcohol and skeletal disease. En: Lieber CS, editor. Metabolic aspects of alcoholism. Lancaster: MTP Press; 1977. p. 135-47. 
4. Resnick D, Niwayama G. Diagnosis of bone and joint disorders. Philadelphia: Saunders; 1981. p. 2833-73.

5. Moran MC. Osteonecrosis of the hip in sickle cell haemoglobinopathy. Am J Orthopedics. 1995;24:18-24.

6. Jones LC, Hungerford DS. Osteonecrosis: etiology, diagnosis, and treatment. Curr Opin Rheumathol. 2004;16:443-9.

7. Liu YF, Chen WM, Lin YF, Yang RC, Lin MW, Li LH, et al. Type II collagen gene variants and inherited osteonecrosis of the fe- moral head. N Eng J Med. 2005;352:2299301.

8. Solomon L. Drug-induced arthropathy and necrosis of the femoral head. J Bone Joint Surg Br. 1973;55B:246-51.

9. Wong GK, Poon WS, Chiu KH. Steroid-induced avascular necrosis of the hip in neurosurgical patients: epidemiological study. ANZ J Surg. 2005;75:409-10.

10. Herring JA, Kim HT, Browne R. Legg-CalvéPerthes disease. J Bone Joint Surg Am. 2004;86A:2103-20.
11. Pais Pais J. La necrópolis de Cueva del Agua. Tabona. 1991;7:209-13.

12. Maca-Meyer N, Arnay de la Rosa M, Rando JC, Flores C, González AM, Cabrera VM, et al. Ancient mtDNA analysis and the origin of the Guanches. Eur J Hum Genet. 2004;12: 155-62.

13. Ortner DJ, Putschar WGJ. Identification of pathological conditions in human slkeletal remains. Smithsonian Contributions to Anthropology. Washington: Smithsonian Institution Press; 1981. p. 28. 